\title{
Causes of fatal childhood accidents in North Staffordshire, 1980-1989
}

\author{
M. J. BANNON*, Y. H. CARTER ${ }^{\dagger}$, K. T. MASON ${ }^{\ddagger}$ \\ *North Staffordshire Health Authority, Newcastle-under-Lyme, ${ }^{\dagger}$ Research Fellow, \\ Keele University, ${ }^{\ddagger}$ Centre for Regional Information and Research, Department of \\ Geography, Keele University, Keele
}

\section{SUMMARY}

Sixty-nine children aged under 15 years were identified from coroners' records as having died as a result of an accident between 1980 and 1989. Road traffic accidents (RTAs) accounted for the majority of cases $(n=38 ; 55 \%$ of total) and in almost all of these, the unsafe behaviour of the child was considered to be at fault. Most fatal accidents occurred between 15.00 and $21.00 \mathrm{hrs}$ and within $2 \mathrm{~km}$ of the child's home; the majority of children killed were not supervised by an adult at the time of the accident. Considerable variation in mortality within the district was observed with several areas having a rate significantly higher than the district as a whole. Head injury was the most commonly recorded cause of death $(n=37,53 \%)$ confirming the importance of head injury as a cause of childhood mortality. Road safety educational and engineering measures as well as adequate adult supervision and awareness could have prevented the vast majority of these accidental deaths. Coroners records are a vital and often poorly utilized source of locally relevant information regarding childhood accidents which should be of use to all interested agencies including child accident prevention groups.

\section{INTRODUCTION}

Accidents are the most important cause of death in children aged 1-15 years in Britain, (Child Accident Prevention Trust, 1989). Evidence suggests that many children who die following an accident were playing unsupervised near their home at the time of the accident (Sharples et al., 1990). These deaths occur in mainly healthy children who might have been expected to have had productive lives and cause immeasurable distress and guilt to the parents and other parties 
involved. The prevention of accidents to children is being increasingly recognized $\stackrel{0}{\vec{a}}$ as an important public health issue and many districts have, as a result, convened $\frac{\mathbb{\Phi}}{2}$ multi-agency child accident prevention groups (Child Accident Prevention $\vec{F}$ Trust, 1991).

One of the primary objectives of these groups should be the collation of locally pertinent data. Incredibly, there is as yet, no single comprehensive source of $\frac{\bar{m}}{\bar{p}}$. readily available data which would easily yield all of the details required for $\stackrel{\varnothing}{\circ}$ such local studies. Office of Population Census and Surveys Classification of Operations and procedures (OPCS) data will certainly yield numbers and causes $\overrightarrow{0}$ of death for various International Classification of Disease (ICD) codes but will not $\overrightarrow{\vec{H}}$ give any information regarding specific accident circumstances nor social back- $\vec{\omega}$ ground of children killed. Hospital data, by and large are limited to those children $\stackrel{\Phi}{\square}$ who, following an accident were admitted to hospital and later died, representing a minority of cases. Child health computer and school health records list all + children who died over a given period of time, but usually do not specify cause of $\mathcal{C}^{\omega}$ death. Coroners' records however, contain basic demographic data of children 0 killed in accidents, pathological information regarding the cause of death and $\stackrel{5}{3}$ detailed descriptions of the circumstances surrounding each accident.

Our aim was to conduct a local accident study in North Staffordshire, by identifying all children from the coroner's records who had died as a result of an accident between 1980 and 1989 , by collating available information from these $\stackrel{\mathscr{\Phi}}{-}$ records regarding details of the child, accident, and injury sustained and to relat $\vec{\theta}$ this information, if possible, to known indices of deprivation for the district.

\section{MATERIALS AND METHODS}

Cases were identified from the coroner's inquisition records for Staffordshire North. The catchment area of this coroner's office is almost identical to that of North Staffordshire Health Authority and consists of the Borough of Newcastleunder-Lyme, the City of Stoke-on-Trent and the Staffordshire Moorlands. North Staffordshire comprises 71 local authority wards. These wards were ranked according to the score they obtained on the underpriviledged areas index devised by Jarman (1983).

The records of all inquests held between 1980 and 1989 inclusive were analysed for children resident in North Staffordshire and aged under 15 years who had 9 died as a 'result of an accident'. Where appropriate, certain cases where the $\frac{D}{0}$ verdict as one of 'misadventure' were also included. Accidental death was also defined according to the diagnostic codes of the ICD (ninth revision) from N800- ON N888. The children who died were then identified from the Office of Population $\tilde{O}$ Censuses and Surveys and the Hospital Activity Analysis. Cases were mapped $\widetilde{N}$ onto ward boundaries according to their usual place of residence as defined by the postcode. Excluded from the study were cases where no verdict was reached, where child abuse was suspected and where medical accidents had occurred. Also $\stackrel{\oplus}{\rightarrow}$ excluded were children who were not residents in North Staffordshire but who 0 died as a result of an accident while visiting the district. 
The following information was extracted from the inquisition proceedings: (1) about the child (name, address, date of birth, sex and socio-economic grouping from father's occupation); (2) about the accident (time, day, date, type and whether child was supervised at the time of the accident); and (3) about the injury (type). The distance from the child's home address to the site of the accident was also determined.

\section{RESULTS}

In the 10-year study period 69 children aged under 15 years had a fatal accident; $56(81 \%)$ were boys. The 10 children injured while visiting the district were excluded from the analysis. The age/sex distribution of the cases studied is demonstrated in Fig. 1.

The mortality rate due to accidents was 7.5 per 100000 for children aged $0-4$ years; 6.4 per 100000 for children aged 5-9 years; and 7.8 per 100000 for those aged 11-14 years. The overall mortality was 7.3 per 100000 children each year.

The overall social class distribution of North Staffordshire according to the 1981 census (Director of Public Health, 1990) is compared with that of the cases studied and is shown in Fig. 2. Children from economically deprived backgrounds had a markedly higher death rate from accidents. Children in social classes IV and V, derived from the head of the household's occupation, represented $62 \%$ of the study group.

The mapping of fatal accidents reveals a pattern that understandably follows that of the underlying population. However, Fig. 3 illustrates the presence of certain concentrations of cases whose existence is not wholly explained by

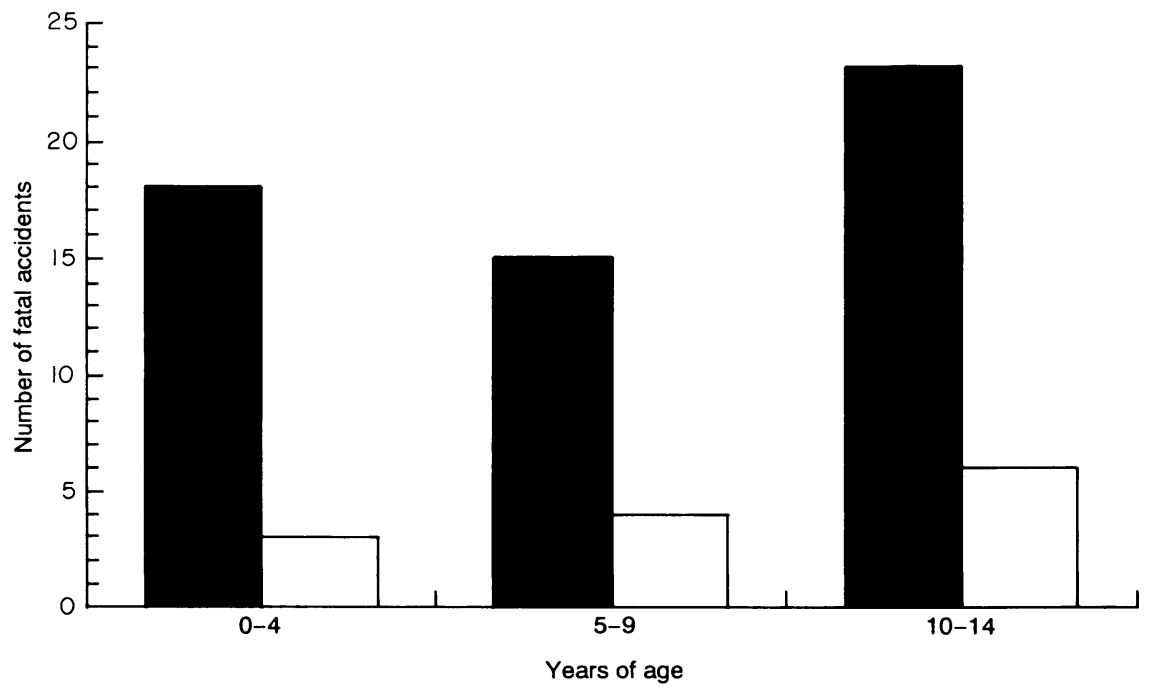

Fig. 1. Age and sex distribution of cases studied; $\square$, female; male. 

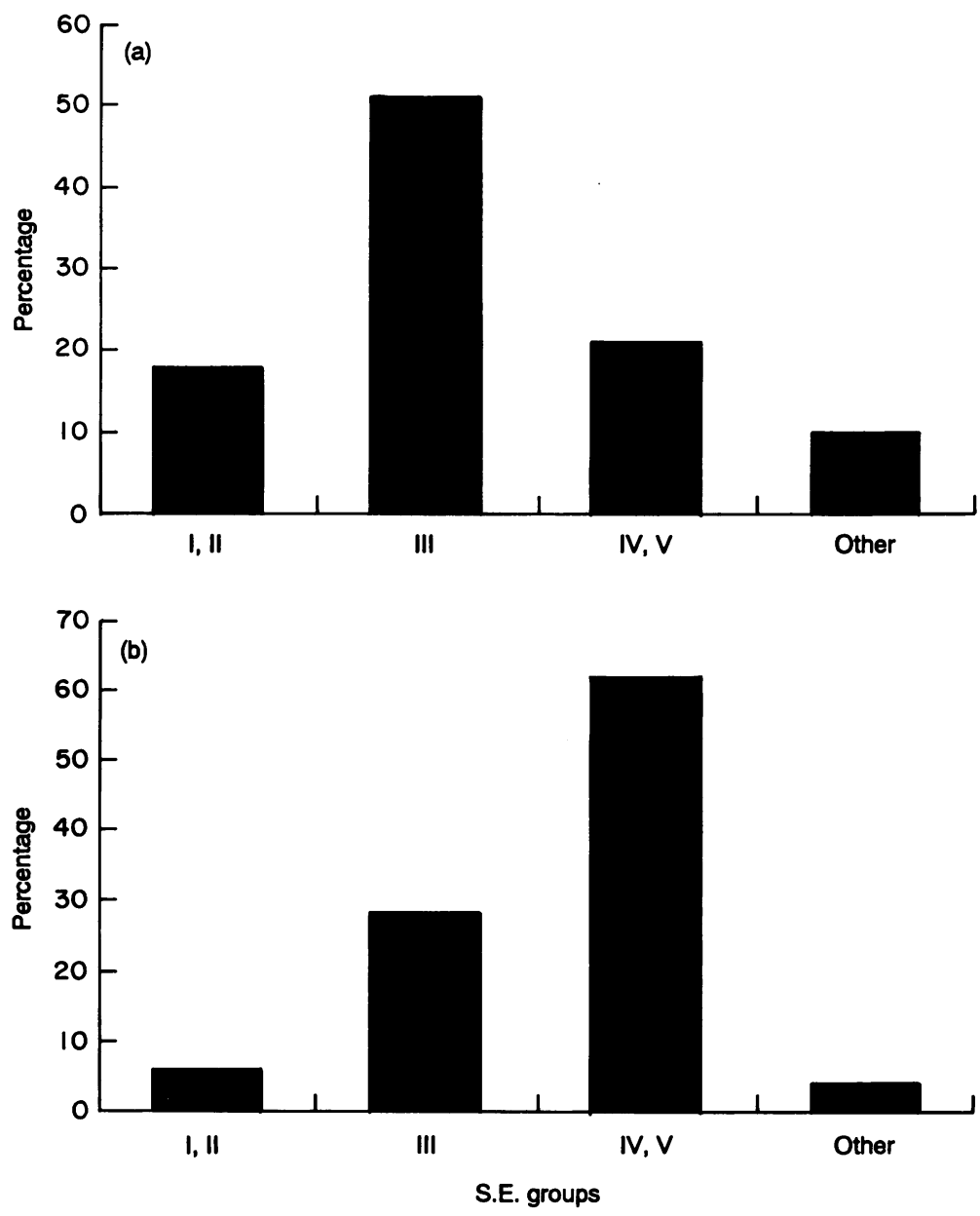

Fig. 2. Social class distribution of North Staffordshire compared with that of study.

population numbers alone. This figure also provides a crude visual comparison with local levels of deprivation (as indicated by Jarman Underpriviledged Area Score) and a certain degree of correspondence may be identified.

The incidence of fatal accidents in relation to the month, day of the week and the time of day, is shown in Fig. 4. Overall, there was no consistent variation in the number of the accidents according to the month or the day, but there was an appreciable variation according to the time of day with $48(70 \%)$ of the accidentso occurring between midday and $9.00 \mathrm{pm}$.

The distance from home to the scene of the accident was recorded in all cases (Fig. 5). The majority of cases occurred close to the child's home, $54(78 \%)$ occurring\% within $2 \mathrm{~km}$.

Figure 6 shows the cause of death in the 69 children. Over half the childreno (38; $55 \%$ ) were fatally injured in RTAs. Accidents to pedestrians were the single 
(a)

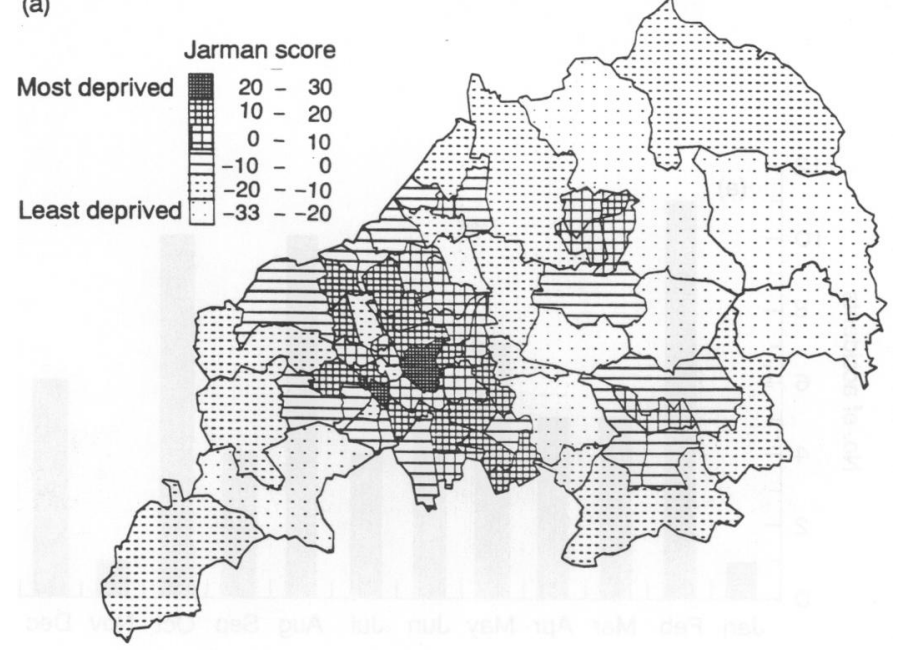

(b)

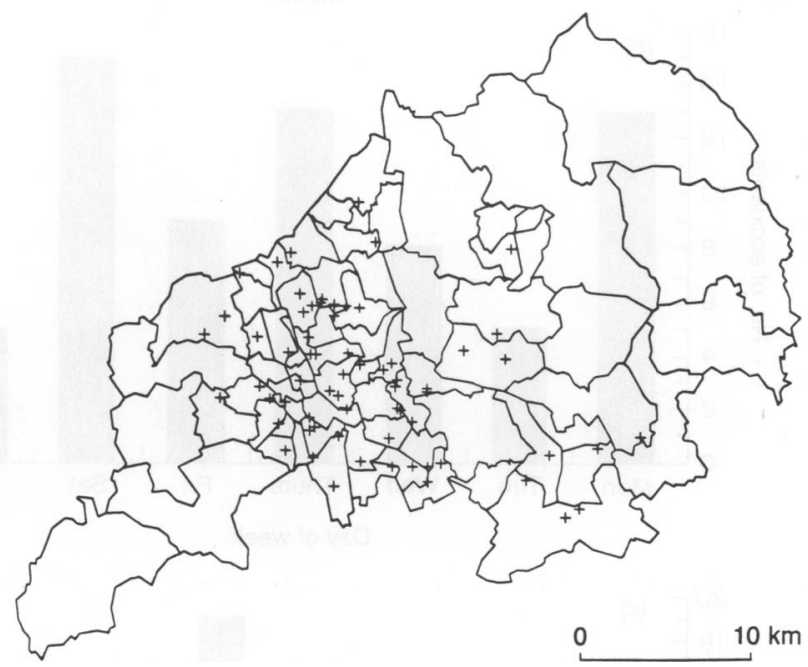

Fig. 3. Illustration of the presence of certain concentrations of cases.

most common cause of fatal RTAs, involving 24 children. One child, who was killed in what was classified as a pedestrian accident, had freed himself from a parked car whilst his parent temporarily left the vehicle. Nine children were killed as cyclists; none of them was recorded as wearing a helmet. One child died as a passenger in a vehicle and was correctly secured in a rear seat child car restraint; the driver of the vehicle was severely injured. The remaining four RTAs included one child who was killed whilst in a pushchair, a second child who was a passenger on a bicycle, a third who was a passenger on a motorcycle and a fourth who fell off a moving tractor. The conclusion of the inquisitions was that in 35 cases $(92 \%)$ of road traffic fatalities, the unsafe behaviour of the child was the 
362 M. J. Bannon et al.
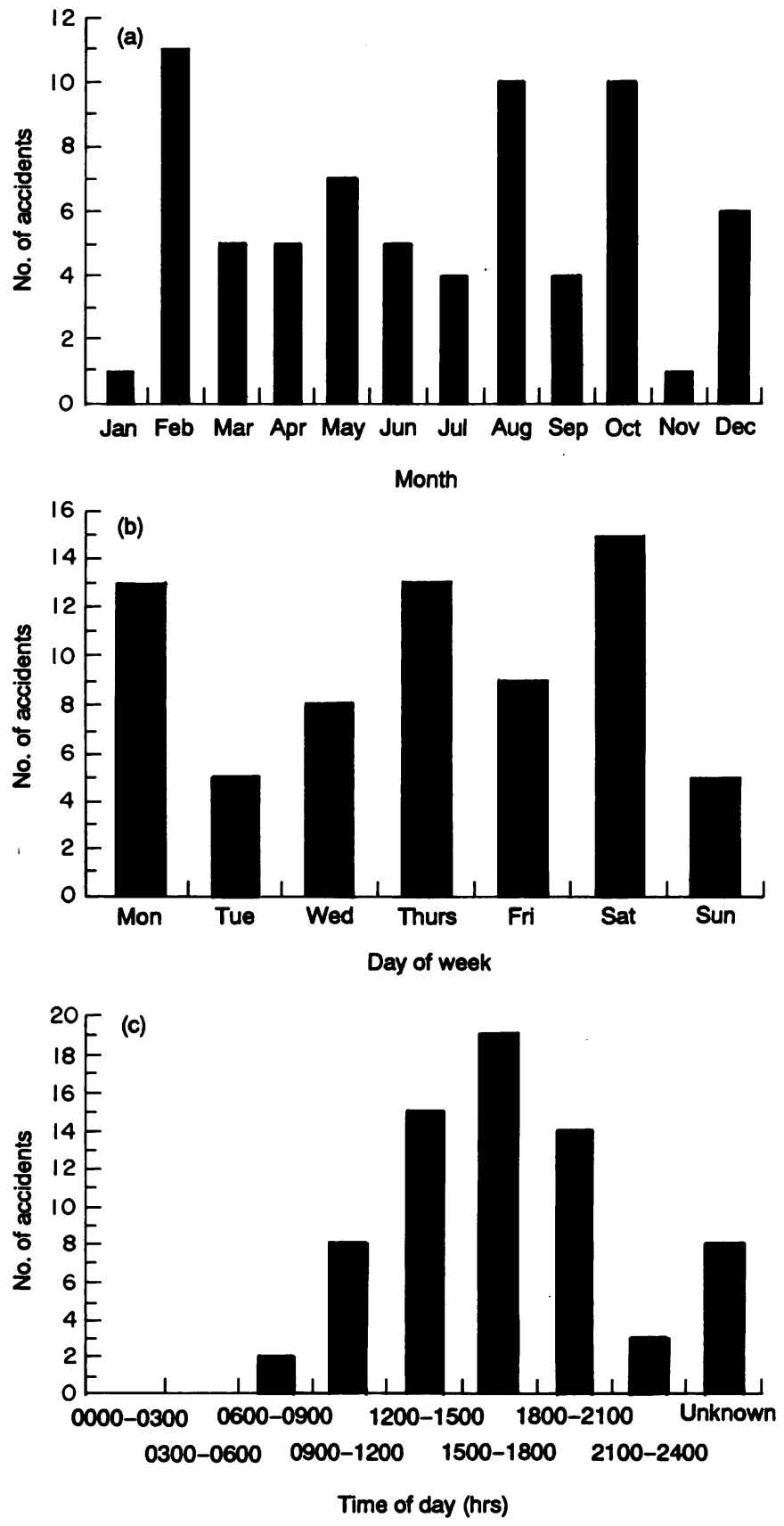

Fig. 4. Incidence of fatal accidents in relation to month, day of week and time of day. 


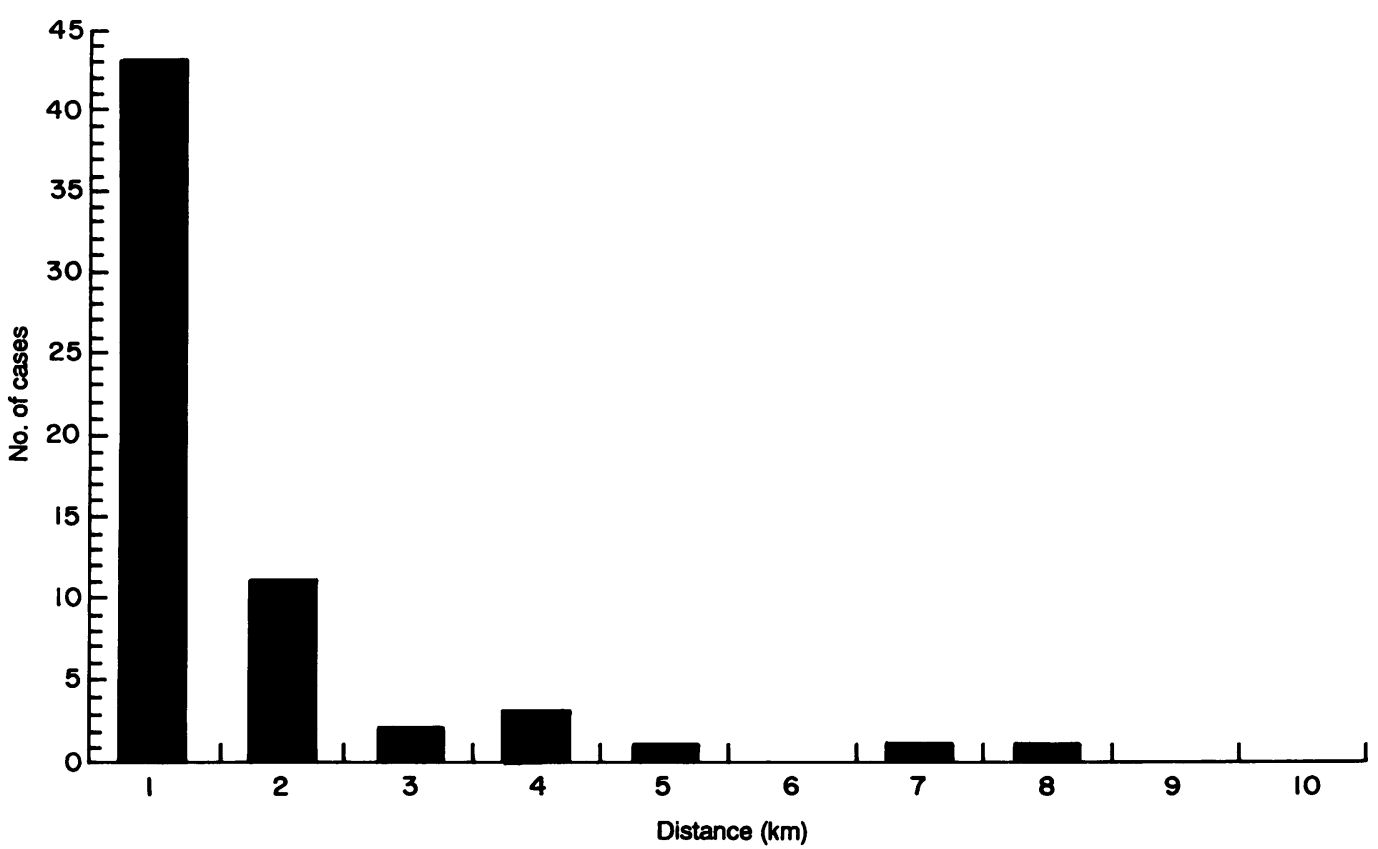

Fig. 5. Distance from childs home to the scene of the accident.

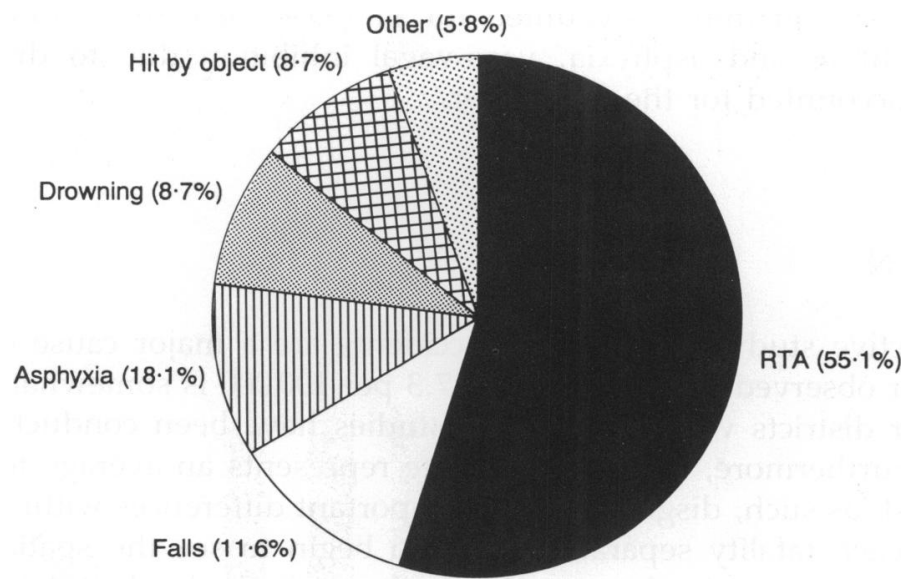

Fig. 6. Pi chart illustrating cause of death.

predominant factor in precipitating the accident. Only six children were supervised at the time of the accident. Alcohol was an important feature in three deaths.

Falls were the second most important cause of fatal childhood accidents, accounting for the deaths of eight children (12\%). Three fatal falls occurred at home two from babywalkers and one from a bannister rail. One accident happened 
at school, one in a playground and one in a factory. In addition, one child fell $\frac{0}{3}$ from a horse. The wearing of a hard hat was not mentioned. Only two children $\stackrel{\varnothing}{\circ}$ were being supervised by an adult at the time of the accident.

Seven fatal accidents were classified as being due to 'asphyxia'. This included $\frac{\mathscr{\omega}}{0}$ two infants who suffocated as a result of bedclothes obstructing their airways, 듬 two infants who were accidentally hanged as a result of bibs becoming entangled $\frac{\overline{\bar{c}}}{\bar{\sigma}}$ in cots and three children who inhaled milk or food. None of these children had $\frac{\mathbb{Q}}{\square}$ been supervised.

Drowning was the cause of death in six children (9\%). Four children drowned $\vec{\circ}$ in ponds, one in an ornamental pond at home. One child was drowned in a canal $\overrightarrow{\vec{H}}$ and one in a public swimming baths. Only one of these children was supervised. $\vec{\omega}$

Six children died as a result of either being hit or crushed by an object. Two $\frac{\Phi}{3}$ children sustained fatal crush injuries at home - one as a result of a falling gate, $\underset{i 0}{\frac{3}{6}}$ the other child was accidentally crushed as a result of playing under a heavy goods vehicle whose driver was unaware of the child's presence. Another child was crushed by a collapsing sandpit. Three children sustained fatal blows fromo other children during play or sport and one child was struck by an iron bar $\rightarrow$ thrown by a friend. No supervision was recorded in these cases.

Finally, two unsupervised children died as a result of inhaling fumes while $\overbrace{\mathbb{R}}$ abusing solvents; one child died from carbon monoxide poisoning while revving a car in a locked garage and one infant was electrocuted as a result of touching the back of an unearthed television set.

In the study period there were no recorded deaths due to fires, burns or scalds:

The inquisitions also recorded where possible the likely cause of death whi was as follows: head injury accounted for 41 (59\%) of cases; multiple injuries, seven cases $(10 \%)$; and asphyxia, vaso-vagal inhibition due to drowning and electrocution accounted for the remainder.

\section{DISCUSSION}

This retrospective study confirms that accidents are a major cause of childhood mortality. Our observed mortality rate of 7.3 per 100000 is somewhat higher than that of similar districts where equivalent studies have been conducted (Sharples $\delta$ et al., 1990). Furthermore, this mortality rate represents an average for the whole study area and, as such, disguises certain important differences within the district. 9 By mapping each fatality separately, we can begin to see the spatial patterning $\frac{D}{0}$ across the district. In itself, this exercise is of only limited value as the pattern of mortality reflects to some large extent the distribution of the underlying local or population. However, by comparing local authority ward level population figures ${ }_{0}$ with the numbers of childhood fatalities occurring within those same wards we $\tilde{\omega}$ are able to derive crude mortality rates for different parts of the district. The outcome of this is a pattern of mortality due to accidents which, at ward level, $\stackrel{0}{\mathbb{D}}$ varies enormously in rate from 0 to 50 deaths per 100000 children.

Unfortunately, because of the small number of cases involved, mortality rates 0 such as these need to be interpreted with extreme caution as there is always the $\frac{0}{\mathbb{D}}$ 
possibility of some chance effect having a substantial influence upon the overall result. To deal with this problem we have subjected our data to a Poisson probability analysis. Briefly, this involves the comparison of the number of cases of childhood fatality in each ward with an expected number of cases in order to see if it is significantly higher or lower. From this analysis the probability of obtaining the observed number of deaths, purely as a result of chance variation, can be computed. This procedure has identified a single ward where an above average level of childhood mortality is statistically 'highly significant' and a further two wards where high rates are 'significant'. Interestingly, the first of these also happens to be the ward with the lowest deprivation score in the district, although the two slightly less significant wards have levels of deprivation that are amongst the worst in the district.

As with previous investigators, we have found that boys are more likely than girls to have a fatal accident although our male:female ratio of $4.3: 1$ is higher than that previously described (Keeling et al., 1985; Levene, 1991). We also found a positive correlation between increasing age and incidence of fatal accidents, indicating that as children get older, they are more likely to have an accident.

The Black Report (Townsend \& Davidson, 1982) emphasized the increasing gradient in childhood mortality due to accidents between social classes I and V. In our series, children from classes IV and V were ten times more likely to die as a result of an accident than those in classes I and II. These differences have been explained on the basis of reduced material resources in the lower classes which place restraint on the level of care and protection which parents can provide for their children. Children in these classes have much less opportunity to play safely under the supervision of their parents and, not uncommonly, are left to their own devices to play especially after school hours. We have shown that the majority of children were fatally injured within a short distance from home, between midday and $9.00 \mathrm{pm}$ and while they were unsupervised by an adult.

Fatal injury sustained as a pedestrian was the commonest cause of death in this and in previous similar studies (Sunderland, 1984). In only a minority of cases was blame directly attributed to the driver, parent or to adverse weather or road conditions. It should be remembered however, that children are more likely to have transport-related accidents as they have reduced danger awareness compared to adults and they are not as skilled in judging speed and distances in busy traffic. Although few driver convictions were made during the study period, it is likely that some of the deaths at least could have been prevented by drivers exercising extra caution when travelling in urban areas where children are playing. The efficacy of preventative measures such as improved road safety for children, increased supervision of children by adults and the provision of safe play areas away from traffic have been proven elsewhere.

Head injury continues to be a significant cause of childhood mortality accounting for $15 \%$ of all childhood deaths and $59 \%$ of the cases in this series. Accidents causing fatal head injuries were RTAs, falls and blows. It is worthy of note that two of the fatal head accidents occurred to children in baby walkers. The hazards associated with the use of baby walkers in young children has already been documented (Gleadhill et al., 1987).

As a result of our findings, we have designed a leaflet to alert parents to the 
hazards of head injury in childhood and which will be distributed by health visitors at the time of the primary visit. We plan to evaluate the usefulness of these leaflets in due course.

Child accident prevention should be a priority for every district health authority One of the prime objectives in child accident strategy is the collection of locallye relevant information. Ideally this would comprise a comprehensive data basen compiled from all available sources. At present, few if any districts, have access to such a resource. In the interim, coroners' records, where available, are a valuable and under-used source of data relevant to child accident prevention issues.

\section{ACKNOWLEDGEMENTS}

The authors wish to thank H. M. Coroner and E. J. Wain, for permission to use hisy records and to gratefully acknowledge the assistance given by his staff duringo the period of this study.

\section{REFERENCES}

Child Accident Prevention Trust. (1989) Basic principles of child accident prevention. Child Accidêñ Prevention Trust, London.

Child Accident Prevention Trust (1991) Approaches to Local Child Accident Prevention Project (ALCAPT) Child Accident Prevention Trust, London.

Director of Public Health. (1990) The Health of North Staffordshire. Annual report of the Director o Public Health.

Gleadhill D. N., Robson W. J., Cudmore R. E. \& Turnock R. R. (1987) Baby walkers .....time to take a stand? Archives of Disease in Childhood 62, 491-449.

Jarman B. (1983) Identification of under-privileged areas. British Medical Journal 286, 1705-1709.

Keeling J. W., Golding J. \& Millier H. K. J. R. (1985) Non-natural deaths in two health districts. Archives of Disease in Childhood 60, 525-529.

Levene S. (1991) Coroners' records of accidental deaths. Archives of Disease in Childhood 66, 1239-1241

Sharples P. M., Storey A., Aynsley-Green A. \& Eyre J. A. (1990) Causes of fatal childhood accidentso involving head injury in Northern region, 1979-86. British Medical Journal 301, 1193-1197.

Sunderland R. (1984) Dying young in traffic. Archives of Disease in Childhood 59, 754-775.

Townsend P. \& Davidson N. (Eds) (1982) Inequalities in Health (The Black Report). Penguin胥 Harmondsworth. 